\title{
Gender Differences in Relations of Smoking Status, Depression, and Suicidality in Korea: Findings from the Korea National Health and Nutrition Examination Survey 2008-2012
}

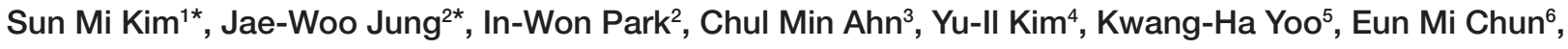 \\ Ji Ye Jung ${ }^{7}$, Young Sik Park ${ }^{8}$, Ju-Heon Park ${ }^{9}$, Jae Yeol Kim ${ }^{2}$, and Korean Smoking Cessation Study Group \\ ${ }^{1}$ Department of Psychiatry, Chung-Ang University College of Medicine, Seoul, Republic of Korea \\ ${ }^{2}$ Department of Internal Medicine, Chung-Ang University College of Medicine, Seoul, Republic of Korea \\ ${ }^{3}$ Division of Pulmonology, Department of Internal Medicine, Kangnam Severance Hospital, Yonsei University College of Medicine, Seoul, Republic of Korea \\ ${ }^{4}$ Department of Internal Medicine, Chonnam National University Hospital, Gwangju, Republic of Korea \\ ${ }^{5}$ Department of Internal Medicine, Konkuk University School of Medicine, Seoul, Republic of Korea \\ ${ }^{6}$ Department of Internal Medicine, Ewha Womans University School of Medicine, Seoul, Republic of Korea \\ ${ }^{7}$ Division of Pulmonology, Department of Internal Medicine, Institute of Chest Disease, Severance Hospital, Yonsei University College of Medicine, \\ Seoul, Republic of Korea \\ ${ }^{8}$ Division of Pulmonology, Department of Internal Medicine, Seoul National University College of Medicine, Seoul, Republic of Korea \\ ${ }^{9}$ Department of Internal Medicine, Ajou University School of Medicine, Suwon, Republic of Korea
}

Objective As mental health problems may play an important role in initiating and maintaining cigarette smoking in females and there are an increasing number of female smokers, we evaluated the relationship between smoking status and mental health problems including depression and suicide ideation in women in Korea.

Methods We analyzed the 5-year cumulative data (19 years of age or older, $\mathrm{n}=32,184)$ from the Korean National Health and Nutrition Examination Survey (KNHANES) conducted from 2008 to 2012. Logistic regression analyses were used to evaluate associations between cigarette smoking status and mental health parameters while controlling for potentially confounding variables.

Results Among current smokers, females showed higher lifetime prevalence in having a depressive episode, a doctor-diagnosed major depression, a current diagnosis of depression, or receiving treatment for depression in comparison with males. In addition, females were more likely to report on having a depressive episode, suicidal ideation and attempts, and psychiatric counselling within the previous year, as compared to males. Female former smokers showed intermediate characteristics in parameters of mental health status within the previous year, ranking between lifetime non-smokers and the current smokers.

Conclusion Identifying the factors related to mental health status among current smokers can increase opportunities for an early intervention and help reduce the prevalence of smoking and increase smoking cessation rates particularly in females. Developing adaptive coping strategies other than smoking in female youth is potentially important in reducing the initiation of smoking.

Psychiatry Investig 2016;13(2):239-246

Key Words Tobacco smoking, Depression, Suicidality, Gender differences, Female smokers.

\section{INTRODUCTION}

Cigarette smoking is the leading cause of premature and

Received: March 18, 2015 Revised: July 20, 2015

Accepted: July 24, 2015 Available online: January 8, 2016

$\triangle$ Correspondence: Jae Yeol Kim, MD, PhD

Department of Internal Medicine, Chung-Ang University Hospital, 102 Heukseok-ro, Dongjak-gu, Seoul 06973, Republic of Korea

Tel: +82-2-6299-1005, Fax: +82-2-825-7571, E-mail: jykimmd@cau.ac.kr

*These authors contributed equally to this work.

(a) This is an Open Access article distributed under the terms of the Creative Commons Attribution Non-Commercial License (http://creativecommons.org/licenses/bync/3.0) which permits unrestricted non-commercial use, distribution, and reproduction in any medium, provided the original work is properly cited. preventable death that can be reduced by smoking cessation. ${ }^{1,2}$ However, in spite of optimal treatment, long-term abstinence rates after a single quit attempt rarely exceed 30\%. ${ }^{3}$ According to the National Health Statistics by Korean Center for Disease Control and Prevention, the prevalence of smoking cigarettes among Korean male and female adults was $43.3 \%$ and $7.4 \%$, respectively, in $2012 .{ }^{4}$ In Korea, smoking rates decreased in all age groups of men and old women, while smoking rates among women aged $20-44$ did not decrease during the period between 1989-2003. ${ }^{5}$ Nevertheless, the gender differences in smoking rate in Korea are high in comparison with other 
countries. ${ }^{6}$ Female smokers are of particular concern because the issue of female smoking is complicated by female reproductive status, menstrual cycle phase, and mental health. ${ }^{7}$ In addition, women are known to experience more difficulty in maintaining smoking cessation. ${ }^{8}$

Mental health problems, especially depression plays an important role in the maintenance and cessation of cigarette smoking in both males and females. So far, there have been many studies on depression as a risk factor for initiating cigarette smoking, on cigarette smoking as a risk factor for depression, as well as on an association between depression and smoking cessation. ${ }^{9-14}$ In the study conducted by Glassman et al., ${ }^{15} 60 \%$ of the participants who were enrolled in a smoking cessation program had past depressive episodes, and they showed twice as high a failure rate in smoking cessation than those without depression. ${ }^{15}$ Depressive mood but not other withdrawal symptoms reportedly increase after stopping smoking, thus prospectively predicting relapse. ${ }^{16}$ The degree of depression is also more likely to be severe among current smokers than non-smokers. ${ }^{17}$

The association between cigarette smoking and suicidality has also been investigated. Smoking is known to be an independent risk factor for suicide, even after controlling for other possible confounding factors, including mental illnesses. ${ }^{18,19}$ Current cigarette smoking may predict suicide attempts in patients with bipolar disorder ${ }^{20}$ as well as major depressive disorder ${ }^{21}$ among a community representative sample. Several studies reported that smoking cessation could cause increased depression and suicidality in the short-term, ${ }^{16,22}$ although others argued that long-term abstinence of several years duration could reverse the risk..$^{23,24}$

In Korea, the death rate due to suicide was 31.7 deaths per 100,000 in 2011, which was the highest rate among the Organization for Economic Co-operation and Development (OECD) countries. ${ }^{25}$ Suicide is the most common cause of death for those under 40 years of age in Korea. ${ }^{10}$ Although Korea has a uniquely high prevalence of smoking cigarettes and a high suicide rate, no study to date has addressed the association between cigarette smoking with mental health problems, including suicidal ideation or attempts. For instance, it is not clear whether cigarette smoking causes more depressive mood and suicidality in females, as compared to males, or whether depression- and suicide-prone females are more attracted to cigarette smoking as a habit. Evaluation of gender differences in the mental health status of smokers using large population data may shed some light on the subject.

We evaluated the relationship between the smoking status and mental health problems including depression and suicidality, and gender differences using the data obtained from a nationally representative sample of Korean adults.

\section{METHODS}

\section{Participants and data collection}

The data analyzed in the study was obtained from the Korean National Health and Nutrition Examination Survey (KNHANES) from 2008 to 2012. The KNHANES is a national surveillance system that has been assessing the health knowledge and behaviors, as well as nutritional status of Koreans since 1998. It is an ongoing, population-based nationwide cross-sectional surveillance system conducted annually by the Korea Center for Disease Control and Prevention. ${ }^{25}$ This survey is a nationwide representative study using a stratified, multi-stage probability sampling design for the selection of household units. Trained investigators conducted surveys in households and the participants completed questionnaires that included a health interview survey, a health behavior survey, and a nutrition survey. Participants also underwent a health examination survey including blood and urine biochemical assays. This survey protocol was approved by the Institutional Review Board of the Korea Centers for Disease Control and Prevention (approval no. 2008-04EXP-01-C, 2009-01CON03-2C, 2010-02CON-21-C, 2011-02CON-06-C, and 201201EXP-01-2C). Informed consents were obtained from all participants.

Among a total of 45,811 participants (20,829 males and 24,982 females) of the KNHANES from 2008 to 2012, 32,184 participants (13,662 males and 18,522 females) who were older than 19 years and responded to smoking-related questionnaire were selected. Among individual components of the health interview questionnaire of KNHANES, we evaluated information on cigarette smoking and mental health. The health interview and health examination were performed by trained medical staff and interviewers at a mobile examination center. Age, sex, income quartile, level of education and marital status were assessed through a questionnaire. Because the KNHANES data were collected and analyzed anonymously, the Institutional Review Board (IRB) of Chung-Ang University Hospital allowed the data analysis without obtaining informed consent.

\section{Study procedures}

Participants were categorized into 1 of 3 mutually exclusive groups depending on their smoking habit: 1) Those who reported having smoked at least 100 cigarettes and used tobacco within the past month ("current smokers"); 2) those who reported having smoked at least 100 cigarettes previously, but no history of tobacco use within the past month ("former smokers"); or 3) those who answered "no" to the question regarding lifetime tobacco use ("lifetime non-smokers").

The items regarding perceived mental well-being included "perceived level of quality of life" (measured by Euro quality 
of life (EuroQol)-visual analogue scale; EQ-VAS; 0: "worst imaginable health state" to 100: "best imaginable health state") and "perceived level of stress" (assessed by the following question: "How much do you feel stressed?" using a fourpoint Likert-type scale (1: "not at all" to 4: "very much"). Mild, moderate, or severe stress levels were defined as responses of 2, 3, or 4 of the Likert-type scale, respectively.

Items regarding depression-related experiences included in the analyses were "lifetime experience of having a depressive episode" (measured by yes-or-no question); "lifetime experience of doctor-diagnosed major depression" (measured by yesor-no question), "lifetime experience of receiving treatment for depression" (measured by yes-or-no question), "having current diagnosis of depression" (measured by yes-or-no question).

The items regarding mental health status within the previous year including depressive episode, suicidal behaviors, and psychiatric counselling within the previous year were also included in the analyses. "Depressive episode within the previous year" was defined by the question about the experience of feeling sadness or hopelessness at least 2 weeks during the past year (measured by yes-or-no question). To assess "suicidal ideation within the previous year", participants were asked whether they had ever seriously wanted to commit suicide during the past year (measured by yes-or-no question). To assess "suicide attempts within the previous year", participants were asked whether they had ever attempted suicide during the previous year (measured by yes-or-no question). In addition, "experience of having counseling in psychiatric clinic within the previous year" (measured by yes-or-no question) was included in the analyses.

Finally, we collected information on the exposure to tobacco smoke that was measured by urine cotinine test. Urine cotinine data were available in 14,077 participants (43.7\%; 6,614 males and 7,463 females).

\section{Statistical analysis}

Statistical analyses were performed using SPSS version 16.0 (SPSS Inc., Chicago, IL, USA). Categorical variables were pre-

Table 1. Baseline characteristics of total participants

\begin{tabular}{|c|c|c|c|c|}
\hline & Current smoker & Former smoker & Non smoker & \\
\hline & $\mathrm{N}=6,899(21.4 \%)$ & $\mathrm{N}=6,355(19.7 \%)$ & $\mathrm{N}=18,930(58.5 \%)$ & $P$ \\
\hline Age & $45.66 \pm 15.47$ & $54.37 \pm 16.46$ & $49.89 \pm 16.72$ & $<0.001$ \\
\hline Sex & & & & $<0.001$ \\
\hline Male & $5,797(84.0 \%)$ & $5,312(83.6 \%)$ & $4,553(13.5 \%)$ & \\
\hline Female & $1,102(16.0 \%)$ & $1,043(16.4 \%)$ & $16,377(86.5 \%)$ & \\
\hline Pack year & $19.64 \pm 16.65$ & $17.95 \pm 21.16$ & 0 & \\
\hline Urine cotinine & $1324.86 \pm 971.87$ & $72.33 \pm 270.35$ & $30.13 \pm 163.32$ & $<0.001$ \\
\hline Urine cotinine in male & $1379.82 \pm 988.93$ & $64.83 \pm 254.49$ & $19.52 \pm 117.37$ & $<0.001$ \\
\hline Urine cotinine in female & $964.02 \pm 759.11$ & $111.76 \pm 339.45$ & $32.17 \pm 170.67$ & $<0.001$ \\
\hline Marital status & & & & $<0.001$ \\
\hline Married (live with partner) & $4792(69.6 \%)$ & $5265(83.0 \%)$ & $13264(70.2 \%)$ & \\
\hline Separated/divorced & $397(5.8 \%)$ & $184(2.9 \%)$ & $624(3.3 \%)$ & \\
\hline Widow/widower & $278(4.0 \%)$ & $331(5.2 \%)$ & $2505(13.2 \%)$ & \\
\hline Never married & $1422(20.6 \%)$ & $564(8.9 \%)$ & $2515(13.3 \%)$ & \\
\hline Household income* & & & & $<0.001$ \\
\hline Highest quartile & $1265(18.6 \%)$ & $1345(21.5 \%)$ & $3836(20.6 \%)$ & \\
\hline Upper middle quartile & $1843(27.1 \%)$ & $1542(24.6 \%)$ & $4640(24.9 \%)$ & \\
\hline Lower middle quartile & $1918(28.3 \%)$ & $1699(27.0 \%)$ & $4966(26.6 \%)$ & \\
\hline Lowest quartile & $1763(26.0 \%)$ & $1699(27.0 \%)$ & $5198(27.9 \%)$ & \\
\hline Level of education & & & & $<0.001$ \\
\hline$\leq$ Elementary school & $1218(17.7 \%)$ & $1575(24.8 \%)$ & $5880(31.2 \%)$ & \\
\hline$\leq$ Middle school & $799(11.6 \%)$ & $796(12.5 \%)$ & $1950(10.3 \%)$ & \\
\hline$\leq$ High school & $2785(40.5 \%)$ & $2094(33.0 \%)$ & $5991(31.7 \%)$ & \\
\hline$\geq$ College & $2067(30.1 \%)$ & $1881(29.6 \%)$ & $5050(26.8 \%)$ & \\
\hline
\end{tabular}

*household income was measured as combined income from all sources of the respondent and her family members and was divided to 4 quartiles according to criteria of each year 
sented as numbers and percentages and continuous variables were expressed as the median and standard deviation (SD). Comparisons of individual groups were made using the Chisquare test and Student's t-test. Binary logistic regression was used after adjustment for age, income quartile, level of education and marital state to evaluate associations between cigarette smoking and mental health problems including depression and suicidality. The results were expressed as odds ratio (OR) and 95\% confidence interval (CI). p value of $<0.05$ was accepted as significant.

\section{RESULTS}

\section{Baseline characteristics}

Of the total 32,184 participants, $42.44 \%(n=13,662)$ were male (Table 1). Current smokers were $21.4 \%$ of total participants and $84.0 \%$ of current smokers were males. Former smokers were $79.7 \%$ of total participants and $83.6 \%$ of former smokers were males. Urine cotinine level showed significant differences between lifetime non-smokers, former smokers, and current smokers. Smoking amounts per day showed good correlation with urine cotinine levels, both in males $(\mathrm{r}=0.369, \mathrm{p}<0.001)$ and $\mathrm{fe}$ males $(r=0.315, p<0.001)$. There were significant differences in age, sex, marital status, income quartile and level of education according to cigarette smoking status $(\mathrm{p}<0.001)$.

\section{Perceived mental well-being in relation to cigarette smoking status}

In males, current smokers reported a lower level of perceived quality of life, as compared to former and lifetime non-smokers (both, $\mathrm{p}<0.001$ ) (Supplementary Figure 1 in the online-only Data Supplement). In females, lifetime non-smokers reported a higher level of perceived quality of life, as compared to current and former smokers (both, $\mathrm{p}<0.001$ ). Current smokers reported a higher level of any degree of perceived stress (mild, moderated, or severe), as compared to former and lifetime nonsmokers both in males and females (Supplementary Figure 2 in the online-only Data Supplement).

\section{Prevalence of depression-related experiences in relation to cigarette smoking status}

In male participants, current and former smokers showed higher prevalence in lifetime experience of having a depressive episode than lifetime non-smokers (6.7\% vs. $5.4 \%$; $\mathrm{OR}=1.267 ; 95 \% \mathrm{CI}, 1.033-1.555$ and $6.7 \%$ vs. $5.4 \%$; $\mathrm{OR}=1.279$; 95\% CI, 1.039-1.573, respectively) (Table 2). Male former smokers had more lifetime experience of doctor-diagnosed major depression, as compared to lifetime non-smokers $(2.0 \%$ vs. $1.3 \%$; $\mathrm{OR}=1.546 ; 95 \% \mathrm{CI}, 1.024-2.332$ ). There was no significant difference in having current diagnosis of depression and lifetime experience of receiving treatment for depression among current-, former-, and lifetime non-smokers in males.

Female current smokers showed higher prevalence in lifetime experience of a depressive episode (28.4\% vs. $19.4 \%$; $\mathrm{OR}=1.744$; 95\% CI, 1.512-2.011) (Table 2), lifetime experience of doctor-diagnosed major depression (8.6\% vs. 5.4\%; $\mathrm{OR}=1.945$; 95\% CI, 1.536-2.463), current diagnosis of depression ( $8.4 \%$ vs. $4.5 \%$; OR=1.838; $95 \% \mathrm{CI}, 1.461-2.314$ ),

Table 2. Prevalence of depression-related experiences in relation to cigarette smoking

\begin{tabular}{|c|c|c|c|c|c|c|}
\hline & \multirow{2}{*}{$\begin{array}{l}\text { Current, } \\
\mathrm{N}(\%)\end{array}$} & \multirow{2}{*}{$\begin{array}{l}\text { Former, } \\
\mathrm{N}(\%)\end{array}$} & \multirow{2}{*}{$\begin{array}{l}\text { Non, } \\
\text { N (\%) }\end{array}$} & \multicolumn{3}{|c|}{ OR $(95 \% \mathrm{CI})^{*}$} \\
\hline & & & & Current vs. non & Current vs. former & Former vs. non \\
\hline Male, $\mathrm{N}$ & 5,797 & 5,312 & 2,553 & & & \\
\hline $\begin{array}{l}\text { Lifetime experience of having } \\
\text { a depressive episode }\end{array}$ & $390(6.7 \%)$ & $420(7.9 \%)$ & $138(5.4 \%)$ & $1.267(1.033-1.555)$ & $0.991(0.849-1.156)$ & $1.279(1.039-1.573)$ \\
\hline $\begin{array}{l}\text { Lifetime experience of doctor- } \\
\text { diagnosed major depression }\end{array}$ & $88(1.5 \%)$ & $108(2.0 \%)$ & $32(1.3 \%)$ & $1.228(0.814-1.851)$ & $0.794(0.587-1.075)$ & $1.546(1.024-2.332)$ \\
\hline Current diagnosis of depression & $93(1.6 \%)$ & $108(2.0 \%)$ & $39(1.5 \%)$ & $0.987(0.674-1.445)$ & $0.883(0.656-1.189)$ & $1.118(0.761-1.641)$ \\
\hline $\begin{array}{l}\text { Lifetime experience of receiving } \\
\text { treatment for depression }\end{array}$ & $27(0.6 \%)$ & $29(0.7 \%)$ & $8(0.4 \%)$ & $1.387(0.624-3.081)$ & $0.961(0.549-1.681)$ & $1.443(0.644-3.234)$ \\
\hline Female, $\mathrm{N}$ & 1,102 & 1,043 & 16,377 & & & \\
\hline $\begin{array}{l}\text { Lifetime experience of having } \\
\text { a depressive episode }\end{array}$ & $313(28.4 \%)$ & $269(25.8 \%)$ & $3171(19.4 \%)$ & $1.744(1.512-2.011)$ & $1.133(0.832-1.378)$ & $1.539(1.328-1.784)$ \\
\hline $\begin{array}{l}\text { Lifetime experience of doctor- } \\
\text { diagnosed major depression }\end{array}$ & $95(8.6 \%)$ & $87(8.3 \%)$ & $880(5.4 \%)$ & $1.945(1.536-2.463)$ & $1.036(0.759-1.413)$ & $1.626(1.255-2.108)$ \\
\hline Current diagnosis of depression & $93(8.4 \%)$ & $70(6.7 \%)$ & $741(4.5 \%)$ & $1.838(1.461-2.314)$ & $1.196(0.860-1.664)$ & $1.775(1.403-2.247)$ \\
\hline $\begin{array}{l}\text { Lifetime experience of receiving } \\
\text { treatment for depression }\end{array}$ & $29(3.5 \%)$ & $23(2.9 \%)$ & $216(1.7 \%)$ & $2.298(1.532-3.446)$ & $1.284(0.728-2.264)$ & $1.789(1.140-2.807)$ \\
\hline
\end{tabular}

*adjusted by age, income quartile, level of education, and marital state 
and lifetime experience of treatment for depression (3.5\% vs. $1.7 \%$; $\mathrm{OR}=2.298$; 95\% CI, 1.532-3.446), as compared to lifetime non-smokers. In addition, female former smokers also showed higher prevalence than lifetime non-smoker in all the above items about depression (Table 2).

\section{Mental health status within the previous year in relation to cigarette smoking}

In male participants, current smokers were more likely to report having depressive episode or suicidal ideation within the past year, as compared to former and lifetime non-smokers (Table 3). However, there was no significant difference between former and lifetime non-smokers in mental health status parameters within the previous year.

Female current smokers were more likely to report a depressive episode ( $28.9 \%$ vs. $17.1 \%$, OR=1.912; $95 \%$ CI, 1.659 2.230 ) (Table 3 ), suicidal ideation ( $35.1 \%$ vs. $18.9 \%, \mathrm{OR}=2.200$; 95\% CI, $1.919-2.522)$, suicide attempts (3.6\% vs. $0.8 \%$, $\mathrm{OR}=3.930$; 95\% CI, 2.701-5.719), and experience of counseling in psychiatric clinic within the previous year ( $4.4 \%$ vs. $2.6 \%$, OR $=1.603$; 95\% CI, 1.175-2.188), as compared to lifetime non-smokers. Female former smokers also showed higher prevalence than lifetime non-smoker in the above 4 items regarding mental health status within the previous year (Table 3). Depressive episode within the previous year and suicidal ideation within the previous year were more prevalent in current than in former smokers in female $(28.9 \%$ vs. $22.2 \%, \mathrm{OR}=1.309$; $95 \% \mathrm{CI}, 1.146-1.494$ and $35.1 \%$ vs. $29.4 \%$, OR=1.360; 95\% CI, 1.199-1.543, respectively) (Table 3).

Annual suicide attempt rate in female current smokers was consistently higher than lifetime non-smoker between 2008 and 2012 (Supplementary Figure 3 in the online-only Data Supplement). However, male participants had no differences in suicide attempt rate each of the five years.

\section{Gender differences in mental health status among current smokers}

Among current smokers, females showed higher prevalence in lifetime experience of having a depressive episode ( $28.4 \%$ vs. $6.7 \%$, $\mathrm{OR}=4.800$; $95 \% \mathrm{CI}, 4.020-5.732$ ) (Table 4), doctor-diagnosed major depression ( $8.6 \%$ vs. $1.5 \%$, $\mathrm{OR}=5.432$; $95 \%$ CI, 3.957-7.457), current diagnosis of depression (8.4\% vs. $1.6 \%, \mathrm{OR}=4.126$; $95 \% \mathrm{CI}, 3.015-5.646)$ and lifetime experience of treatment for depression ( $3.5 \%$ vs. $0.6 \%, \mathrm{OR}=4.715$; 95\% CI, 2.682-8.289), as compared to males. Furthermore, with respect to mental health status within the previous year, females were more likely to report depressive episode (28.9\% vs. $11.1 \%, \mathrm{OR}=2.839 ; 95 \% \mathrm{CI}, 2.411-3.342$ ), suicidal ideation (35.1\% vs. $12.4 \%, \mathrm{OR}=3.266 ; 95 \% \mathrm{CI}, 2.792-3.819$ ), suicide attempts (3.6\% vs. $0.9 \%, \mathrm{OR}=3.135 ; 95 \% \mathrm{CI}, 2.019-4.867)$ and

Table 3. Mental health status within the previous year in relation to cigarette smoking in males and females

\begin{tabular}{|c|c|c|c|c|c|c|}
\hline & \multirow{2}{*}{$\begin{array}{l}\text { Current, } \\
\mathrm{N}(\%)\end{array}$} & \multirow{2}{*}{$\begin{array}{l}\text { Former, } \\
\mathrm{N}(\%)\end{array}$} & \multirow{2}{*}{$\begin{array}{l}\text { Non, } \\
\text { N (\%) }\end{array}$} & \multicolumn{3}{|c|}{ OR $(95 \% \mathrm{CI})^{*}$} \\
\hline & & & & Current vs. non & Current vs. former & Former vs. non \\
\hline Males, $\mathrm{N}$ & 5,797 & 5,312 & 2,553 & & & \\
\hline $\begin{array}{l}\text { Depressive episode within } \\
\text { the previous year }\end{array}$ & $644(11.1 \%)$ & $492(9.3 \%)$ & $211(8.3 \%)$ & $1.364(1.154-1.611)$ & $1.309(1.146-1.494)$ & $1.042(0.874-1.242)$ \\
\hline $\begin{array}{l}\text { Suicidal ideation within } \\
\text { the previous year }\end{array}$ & $720(12.4 \%)$ & $578(10.9 \%)$ & $213(8.4 \%)$ & $1.564(1.325-1.845)$ & $1.360(1.199-1.543)$ & $1.150(0.967-1.367)$ \\
\hline $\begin{array}{l}\text { Suicide attempts within } \\
\text { the previous year }\end{array}$ & $52(0.9 \%)$ & $36(0.7 \%)$ & $21(0.8 \%)$ & $1.005(0.593-1.701)$ & $1.404(0.893-2.209)$ & $0.715(0.406-1.262)$ \\
\hline $\begin{array}{l}\text { Experience of having } \\
\text { counseling in psychiatric } \\
\text { clinic within the previous year }\end{array}$ & $84(1.4 \%)$ & $75(1.4 \%)$ & $41(1.6 \%)$ & $0.925(0.630-1.357)$ & $0.935(0.671-1.303)$ & $0.989(0.660-1.428)$ \\
\hline Females, $\mathrm{N}$ & 1,102 & 1,043 & 16,377 & & & \\
\hline $\begin{array}{l}\text { Depressive episode within } \\
\text { the previous year }\end{array}$ & $318(28.9 \%)$ & $231(22.2 \%)$ & $2794(17.1 \%)$ & $1.912(1.659-2.203)$ & $1.309(1.146-1.494)$ & $1.405(1.203-1.642)$ \\
\hline $\begin{array}{l}\text { Suicidal ideation within } \\
\text { the previous year }\end{array}$ & $386(35.1 \%)$ & $306(29.4 \%)$ & $3089(18.9 \%)$ & $2.200(1.919-2.522)$ & $1.360(1.199-1.543)$ & $1.797(1.554-2.078)$ \\
\hline $\begin{array}{l}\text { Suicide attempts within } \\
\text { the previous year }\end{array}$ & $40(3.6 \%)$ & $22(2.1 \%)$ & $127(0.8 \%)$ & $3.930(2.701-5.719)$ & $1.404(0.893-2.209)$ & $2.614(1.643-4.157)$ \\
\hline $\begin{array}{l}\text { Experience of having } \\
\text { counseling in psychiatric } \\
\text { clinic within the previous year }\end{array}$ & $49(4.4 \%)$ & $47(4.5 \%)$ & $433(2.6 \%)$ & $1.603(1.175-2.188)$ & $0.935(0.671-1.303)$ & $1.671(1.225-2.281)$ \\
\hline
\end{tabular}

*adjusted by age, income quartile, level of education, and marital state 
psychiatric counselling within the previous year $(4.4 \%$ vs. $1.4 \%, \mathrm{OR}=2.856 ; 95 \% \mathrm{CI}, 1.957-4.167$ ), as compared to males.

\section{DISCUSSION}

We evaluated the relationship between smoking and mental health status among Korean adults from the nationwide surveillance system (KNHANES) from 2008 to 2012 that represents the general Korean population. Smoking status collected by personal interview surveys strongly correlated with reported smoking status and urine cotinine levels. Selection of only those who responded to questionnaire for smoking status resulted in female dominance (18,522 females and 13,662 males) in the analyses.

The cumulative rate of current smoking was $42.2 \%$ in males and $5.9 \%$ in females. Considering the converging trend of male and female smoking prevalence in economically advanced countries, the female smoking rate in Korea is still low. ${ }^{26}$ Current smokers were younger, fewer were in high-income quartile, and fewer were married than lifetime non-smokers. There have been several studies on the relationship between socioeconomic status and smoking. ${ }^{5,27,28}$ Smoking gradually increases from higher to lower socioeconomic groups. ${ }^{5,27,28}$

Lower level of perceived quality of life is associated with higher odds of smoking initiation and lower odds of successful smoking cessation. ${ }^{13}$ Schmitz et al. ${ }^{29}$ reported that smoking status as well as the severity of nicotine dependence in smokers are associated with health-related quality of life, disability, and associated psychiatric disorders. The negative relationship between smoking and quality of life was also observed in the study. In addition, our data suggested that current smokers experience higher rates of any degree of perceived stress regardless of gender. Stress is one of the most important induc- ers for cigarette smoking. ${ }^{30}$ However, according to the results of this study, smoking seems to aggravate instead of lessen the level of perceived stress.

Male current smokers showed higher prevalence in lifetime experience of having a depressive episode than former and lifetime non-smokers. Female lifetime smokers (both former smokers and current smokers) showed higher prevalence in all parameters regarding depression-related experiences: lifetime experience of a depressive episode; lifetime experience of doctor-diagnosed major depression; current diagnosis of depression; and lifetime experience of treatment for depression than female lifetime non-smokers.

A controversy exists on whether depression is a risk factor for smoking or that smoking is a risk factor for depression. Escobedo et al. ${ }^{31}$ showed an association between the start of smoking and depression in a 4 year prospective cohort study for adolescents. While the start of smoking was $19.0 \%$ in adolescents with depression, the start of smoking was $12.9 \%$ in adolescents without depression and thus, the likelihood of smoking initiation during adolescence was positively associated with depression scores. This makes us believe that depression may lead to a greater likelihood of starting to smoke.

In addition to higher prevalence of depressive episodes and suicidal ideation within the previous year among female current-smokers, which were also observed in male currentsmokers, the female current-smokers were more likely to report suicidal ideation, suicide attempts and psychiatric counselling within the previous year, as compared to female lifetime non-smokers. In particular, actual suicide attempts increased 4 -fold in female current smokers, as compared to non-smokers and 3-fold compared to male current smokers. Wilhelm et al..$^{32}$ reported that current smokers had a 2 -fold increased risk of a depressive episode within the past 12 months, as com-

Table 4. Gender differences in mental health status among current smokers

\begin{tabular}{|c|c|c|c|}
\hline & Male & Female & \multirow{2}{*}{$\mathrm{OR}(95 \% \mathrm{CI})^{*}$} \\
\hline & $\mathrm{N}=5,797(42.4 \%)$ & $\mathrm{N}=1,102(5.9 \%)$ & \\
\hline \multicolumn{4}{|l|}{ Depression-related experiences } \\
\hline Lifetime experience of having a depressive episode & $390(6.7 \%)$ & $313(28.4 \%)$ & $4.800(4.020-5.732)$ \\
\hline Lifetime experience of doctor-diagnosed major depression & $88(1.5 \%)$ & $95(8.6 \%)$ & $5.432(3.957-7.457)$ \\
\hline Current diagnosis of depression & $93(1.6 \%)$ & $93(8.4 \%)$ & $4.126(3.015-5.646)$ \\
\hline Lifetime experience of receiving treatment for depression & $27(0.6 \%)$ & $29(3.5 \%)$ & $4.715(2.682-8.289)$ \\
\hline \multicolumn{4}{|l|}{ Mental health status within the previous year } \\
\hline Depressive episode within the previous year & $644(11.1 \%)$ & $318(28.9 \%)$ & $2.839(2.411-3.342)$ \\
\hline Suicidal ideation within the previous year & $720(12.4 \%)$ & $386(35.1 \%)$ & $3.266(2.792-3.819)$ \\
\hline Suicide attempts within the previous year & $52(0.9 \%)$ & $40(3.6 \%)$ & $3.135(2.019-4.867)$ \\
\hline $\begin{array}{l}\text { Experience of having counseling in psychiatric clinic within } \\
\text { the previous year }\end{array}$ & $84(1.4 \%)$ & $49(4.4 \%)$ & $2.856(1.957-4.167)$ \\
\hline
\end{tabular}


pared to lifetime non-smokers and former-smokers. It is noteworthy that suicide attempt was higher in current-smokers than in lifetime non-smokers in female in not only from a 5 -year cumulative data but also in each year of the data.

Though the mechanism is unclear, tobacco use is one of the strongest predictors of future suicidal behavior. ${ }^{11}$ Malone et al. ${ }^{33}$ demonstrated that the association between cigarette smoking and the presence of suicidal behavior may be related to lower brain serotonin function in smokers with depression. Lifetime female smokers with major depression had more severe illness, more suicidal ideation and attempts than lifetime non-smokers. ${ }^{12}$ In a web-based anonymous self-reported survey that evaluated 72,623 South Korean adolescents aged 1218 years, the amount of smoking had a positive relationship with suicidal ideation. In addition, smoking female adolescents had a 1.99 times higher rate of suicidal ideation than smoking male adolescents. ${ }^{10}$ A study of the relationship between cigarettes and suicide in 100,000 middle-aged, female registered nurses demonstrated that smoking was associated with increased depression rate and related suicide attempt as dose dependent relationship between smoking amount and suicide in female. ${ }^{34}$ In this study, female former smokers showed intermediate characteristics, ranking between the lifetime nonsmokers and the current smokers in all the parameters of mental health status within the previous year. Otherwise, there were no statistical differences in these parameters between former and lifetime non-smokers in males. It is denoted that vulnerability to psychological distress is more closely associated with smoking initiation in females than males. In addition, it is suggested that developing adaptive coping strategies for stress in female youths other than smoking cigarette is important to reduce initiation of smoking.

The results on gender differences in mental health status among current smokers were noteworthy. Among current smokers, females showed higher prevalence in lifetime experience of depressive episode, lifetime experience of doctor-diagnosed major depression, current diagnosis of depression, lifetime experience of treatment for depression in comparison with males. In addition, females were more likely to report depressive episode, suicidal behaviors, and psychiatric counselling within the previous year, as compared to males.

Female smoking rate in Korea is still lower, as compared to other economically advanced countries. Cultural differences in female empowerment are known to influence smoking behaviors, resulting in gender differences in the prevalence of smoking, especially in Asian countries. ${ }^{35-37}$ In Korea, smoking is thought to be necessary for social conformity in social and business settings for men, and considered as contrary to traditional female roles as wife and mother. ${ }^{36}$ Korean women who are lifetime smokers despite a social gender-based stig- ma associated with female smoking seem may have higher perceived stress negatively impacting mental health. This is in compare with males who may have acceptance of their smoking habits and do not feel a negative social pressure for their habit. We propose that it is necessary to introduce strong preventive methods against the initiation of smoking, as well as urgent interventional evaluation of mental health in female current smokers in order to increase smoking cessation rate. Substances used for coping, such as drinking alcoholic beverages and smoking cigarettes, are positively associated with suicidal ideation and attempts in both male and female adolescents, as well as adults. ${ }^{38,39}$ Therefore, developing adaptive coping strategies in female youths other than smoking is important in order to reduce initiation of smoking. In addition, proper evaluation and management of mental health problems among female current smokers may lead to smoking cessation.

\section{Limitations}

The present study had several limitations. Because the KNHANES is a cross-sectional survey, the association of many positive factors with smoking does not imply causality. For this purpose, longitudinal cohort studies may be required. Smoking status was evaluated by personal interview. Although the smoking status showed strong correlation with the urine cotinine level, there was overlapping of urine cotinine level between current and former smokers, especially in female participants. Some female current smokers may have under-reported their smoking status possibly because of being embarrassed at the interview. This has been documented to occur in various face-to-face surveys, for example ones for detecting high-risk behaviors among women. ${ }^{11,40}$ Another shortcoming of our study may be that the KNHANES data set has not been designed with quality control for all steps of data acquisition and management (including survey administration, data collection, laboratory analysis and data processing as well as internal quality assurance and control procedures).

\section{Conclusion}

The results suggested that identifying the factors related to mental health status among current smokers could increase opportunities for early intervention, which can help reduce the prevalence of smoking and increase the smoking cessation rate, especially in females. The results also indicated that developing adaptive coping strategies in young females other than smoking is important in order to reduce initiation of smoking. Future studies are needed to examine whether improving coping skills and managing mental health problems can increase the smoking cessation rate, especially in females. 


\section{Supplementary Materials}

The online-only Data Supplement is available with this article at http://dx.doi.org/10.4306/pi.2016.13.2.239.

\section{REFERENCES}

1. Center for Disease Control and Prevention (CDC). Annual smokingattributable mortality, years of potential life lost, and productivity losses--United States, 1997-2001. MMWR Morb Mortal Wkly Rep 2005; 54:625-628.

2. Doll R, Peto R, Boreham J, Sutherland I. Mortality in relation to smoking: 50 years' observations on male British doctors. BMJ 2004;328:1519.

3. Steinberg MB, Schmelzer AC, Richardson DL, Foulds J. The case for treating tobacco dependence as a chronic disease. Ann Intern Med 2008; 148:554-556.

4. Ministry of Health and Welfare of Korea \& Korean Center for Disease Control and Prevention. 2012 Korea Health Statistics. Seoul: Ministry of Health and Welfare of Korea; 2013.

5. Khang YH, Cho HJ. Socioeconomic inequality in cigarette smoking: trends by gender, age, and socioeconomic position in South Korea, 1989-2003. Prev Med 2006;42:415-422.

6. French DJ, Jang SN, Tait RJ, Anstey KJ. Cross-national gender differences in the socioeconomic factors associated with smoking in Australia, the United States of America and South Korea. Int J Public Health 2013;58:345-353.

7. Perkins KA, Levine M, Marcus M, Shiffman S, D’Amico D, Miller A, et al. Tobacco withdrawal in women and menstrual cycle phase. J Consult Clin Psychol 2000;68:176-180.

8. Fiore M, Bailey W, Cohen S, Dorfman S, Goldstein M, Gritz E, et al. Treating tobacco use and dependence: quick reference guide for clinicians. Rockville, MD: US Department of Health and Human Services, The Public Health Service; 2000.

9. Kenney BA, Holahan CJ, Holahan CK, Brennan PL, Schutte KK, Moos RH. Depressive symptoms, drinking problems, and smoking cessation in older smokers. Addict Behav 2009;34:548-553.

10. Kang EH, Hyun MK, Choi SM, Kim JM, Kim GM, Woo JM. Twelvemonth prevalence and predictors of self-reported suicidal ideation and suicide attempt among Korean adolescents in a web-based nationwide survey. Aust N Z J Psychiatry 2015;49:47-53.

11. Husky MM, Guignard R, Beck F, Michel G. Risk behaviors, suicidal ideation and suicide attempts in a nationally representative French sample. J Affect Disord 2013;151:1059-1065.

12. He Q, Yang L, Shi S, Gao J, Tao M, Zhang K, et al. Smoking and major depressive disorder in Chinese women. PLoS One 2014;9:e106287.

13. Goldenberg M, Danovitch I, IsHak WW. Quality of life and smoking. Am J Addict 2014;23:540-562.

14. Ziedonis D, Hitsman B, Beckham JC, Zvolensky M, Adler LE, AudrainMcGovern J, et al. Tobacco use and cessation in psychiatric disorders: National Institute of Mental Health report. Nicotine Tob Res 2008; 10:1691-1715.

15. Glassman AH, Stetner F, Walsh BT, Raizman PS, Fleiss JL, Cooper TB, et al. Heavy smokers, smoking cessation, and clonidine. Results of a double-blind, randomized trial. JAMA 1988;259:2863-2866.

16. Hughes JR. Effects of abstinence from tobacco: etiology, animal models, epidemiology, and significance: a subjective review. Nicotine Tob Res 2007;9:329-339.

17. Brown C, Madden PA, Palenchar DR, Cooper-Patrick L. The association between depressive symptoms and cigarette smoking in an urban primary care sample. Int J Psychiatry Med 2000;30:15-26.

18. Boden JM, Fergusson DM, Horwood LJ. Cigarette smoking and suicidal behaviour: results from a 25-year longitudinal study. Psychol Med 2008;38:433-439.

19. Clarke DE, Eaton WW, Petronis KR, Ko JY, Chatterjee A, Anthony JC. Increased risk of suicidal ideation in smokers and former smokers compared to never smokers: evidence from the Baltimore ECA followup study. Suicide Life Threat Behav 2010;40:307-318.

20. Baek JH, Eisner LR, Nierenberg AA. Smoking and suicidality in subjects with bipolar disorder: results from the National Epidemiologic Survey on Alcohol and Related Conditions (NESARC). Depress Anxiety 2013;30:982-990.

21. Baek JH, Eisner LR, Nierenberg AA. Smoking and suicidality in subjects with major depressive disorder: results from the National Epidemiologic Survey on Alcohol and Related Conditions (NESARC). J Affect Disord 2013;150:1158-1166.

22. Tsoh JY, Humfleet GL, Munoz RF, Reus VI, Hartz DT, Hall SM. Development of major depression after treatment for smoking cessation. Am J Psychiatry 2000;157:368-374.

23. Berlin I, Covey LS, Donohue MC, Agostiv V. Duration of smoking abstinence and suicide-related outcomes. Nicotine Tob Res 2011;13:887-893.

24. Covey LS, Berlin I, Hu MC, Hakes JK. Smoking and suicidal behaviours in a sample of US adults with low mood: a retrospective analysis of longitudinal data. BMJ Open 2012;2.

25. Kweon S, Kim Y, Jang MJ, Kim K, Choi S, Chun C, et al. Data resource profile: the Korea National Health and Nutrition Examination Survey (KNHANES). Int J Epidemiol 2014;43:69-77.

26. Morley KI, Hall WD. Explaining the convergence of male and female smoking prevalence in Australia. Addiction 2008;103:487-495.

27. Laaksonen M, Rahkonen O, Karvonen S, Lahelma E. Socioeconomic status and smoking: analysing inequalities with multiple indicators. Eur J Public Health 2005;15:262-269.

28. Stronks K, van de Mheen HD, Looman CW, Mackenbach JP. Cultural, material, and psychosocial correlates of the socioeconomic gradient in smoking behavior among adults. Prev Med 1997;26:754-766.

29. Schmitz N, Kruse J, Kugler J. Disabilities, quality of life, and mental disorders associated with smoking and nicotine dependence. Am J Psychiatry 2003;160:1670-1676.

30. MiYang J, HyeonCheol J, Lee K, Yim J. The acute effect of smoking a single cigarette on vascular status, $\mathrm{SpO}$, and stress level. Med Sci Monit 2014;20:601-607.

31. Escobedo LG, Reddy M, Giovino GA. The relationship between depressive symptoms and cigarette smoking in US adolescents. Addiction 1998;93:433-440.

32. Wilhelm K, Mitchell P, Slade T, Brownhill S, Andrews G. Prevalence and correlates of DSM-IV major depression in an Australian national survey. J Affect Disord 2003;75:155-162.

33. Malone KM, Waternaux C, Haas GL, Cooper TB, Li S, Mann JJ. Cigarette smoking, suicidal behavior, and serotonin function in major psychiatric disorders. Am J Psychiatry 2003;160:773-779.

34. Hemenway D, Solnick SJ, Colditz GA. Smoking and suicide among nurses. Am J Public Health 1993;83:249-251.

35. Hitchman SC, Fong GT. Gender empowerment and female-to-male smoking prevalence ratios. Bull World Health Organ 2011;89:195-202.

36. Kim SS, Son H, Nam KA. Personal factors influencing Korean American men's smoking behavior: addiction, health, and age. Arch Psychiatr Nurs 2005;19:35-41.

37. Pampel FC. Global patterns and determinants of sex differences in smoking. Int J Comp Sociol 2006;47:466-487.

38. Kim SM, Han DH, Trksak GH, Lee YS. Gender differences in adolescent coping behaviors and suicidal ideation: findings from a sample of 73,238 adolescents. Anxiety Stress Coping 2014;27:439-454.

39. King RA, Schwab-Stone M, Flisher AJ, Greenwald S, Kramer RA, Goodman SH, et al. Psychosocial and risk behavior correlates of youth suicide attempts and suicidal ideation. J Am Acad Child Adolesc Psychiatry 2001;40:837-846.

40. Yeganeh N, Dillavou C, Simon M, Gorbach P, Santos B, Fonseca R, et al. Audio computer-assisted survey instrument versus face-to-face interviews: optimal method for detecting high-risk behaviour in pregnant women and their sexual partners in the south of Brazil. Int J STD AIDS 2013;24:279-285. 